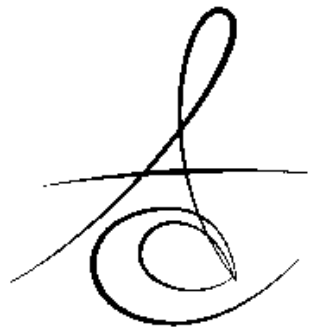

\title{
SABİT PROTETİK RESTORASYONLARIN İN VİVO ÇALIŞMALAR İLE DEĞERLENDİRİLMESİ
}

IN VIVO STUDIES' CRITERIA IN FIXED PARTIAL PROSTHETIC DENTISTRY

Yrd. Doç. Dr. Ayşe KOÇAK-BÜYÜKDERE*

Prof. Dr. Atilla SERTGÖZ ${ }^{*}$

Makale Kodu/Article code: 2110

Makale Gönderilme tarihi: 29.01.2015

Kabul Tarihi: 16.06 .2015

\section{ÖZET}

Günümüzde, hastaların fonksiyonel ve estetik ihtiyaçlarının karşılanması amaçlanmaktadır. Kullanılan malzemelerin klinik başarıları onların uzun dönem ağızda başarılı şekilde kullanılabilmeleri ile yakından ilişkilidir. Bu süre içinde restorasyonların inceleme kriterleri bilimsel olarak kabul edilen California Dental Association (CDA), United States Public Health Service (USPHS) kriterleri veya modifiye USPHS kriterlerinden biriyle belirlenmektedir. $\mathrm{Bu}$ derlemede klinik çalışmalarda kullanılan kriterler ve çalışmalarda kullanım şekilleri anlatılmıştır.

Anahtar Kelimeler: Sabit protetik restorasyonlar, in vivo, modifiye USPHS kriterleri

\section{ABSTRACT}

Nowadays increasing elemental of esthetics, new materials have been introduced in dentistry. However these materials have to be tested whether they are acceptable in clinically in long term period. For this reason, some clinical success criterias such as California Dental Association (CDA), United States Public Health Service (USPHS) criteria and modified USPHS have been used to determine long term survival. This review article describes clinical technique and criterias.

Key Words: Fixed partial dentures, in-vivo, modified USPHS criteria

\section{GİRIŞ}

Sabit protetik restorasyonların, uzun dönem başarılarını değerlendiren klinik çalışmalar retrospektif ve prospektif olmak üzere iki farklı şekilde yapılabilir. Retrospektif çalışmaların en büyük dezavantajı hasta bilgilerinde bazı eksikliklerin olabilmesidir. Prospektif çalışmanın dezavantajı ise pilot çalışma için de ayrı bir bütçenin ayrılmasıdır. ${ }^{1}$

Uzun dönem başarısı araştırılan bir malzemenin, kısa dönemli bir in vitro çalışma sonucunda belirlenmesi mümkün değildir. Ayrıca in vitro çalışmalardan çıkan sonuçlar her zaman klinik sonuçları desteklememektedir. Bu yüzden in vitro çalışmalar, in vivo çalışmalarla desteklenmelidir. 20. yüzyılın ortalarında oluşturulan etik kurallara in vivo çalışmalarda uyulmalıdır. Araştırmacılar çalışmalarına başlamadan önce hastalarını yapılacak işlem hakkında bilgilendirmek zorundadır. ${ }^{2,3}$ Helsinki kurallarında "her insanın üzerinde yapılacak bilimsel çalışma hakkında bilgisi olma gerekliliği" ifadesi kullanılmıştır., ${ }^{4,5}$

Diş hekimliğinde kullanılan malzemelerin in vitro çalışmalarda sağlıklı değerlendirilebilmeleri için mümkün olduğu kadar standart olması amaçlanmıştır. ${ }^{6}$ Klinikte kullanılan malzemelerde de standart oluşturmak için 1977 yılında Dünya Dişhekimleri Federasyonu (World Dental Federation: FDI) her malzeme için belirli özellikler belirlemiş ve malzemelerin bu özellikleri taşıma şartı istenmiştir. ${ }^{5}$ Kullanılacak materyal hastanın estetiği yanında fonksiyon ve fonasyon ihtiyaçlarını karşılamalıdır. Restorasyonların doku uyumu iyi olmalı, toksik olmamalı, ağız ısında değişken olmamalı, dayanıklı olmalı, renk değişikliğine uğramamalı, periodontal açıdan sorun yaratmamalıdır. ${ }^{7,8}$

Klinik çalışmalarda standart oluşturmayı sağlamak için aynı sistemik duruma sahip olan hastalara aynı tip malzemelerin kullanılması doğru bir yaklaşım olur. ${ }^{9}$ Böylece restorasyonların ağızda kalma süreleri ve klinik olarak kabul edilip edilmemeleri daha sağlıklı olarak karşılaştırılabilir. Genellikle sağlıklı bireyler seçilir veya seçilen bireylerde aynı tip hastalığın olmasına

* Recep Tayyip Erdoğan Üniversitesi, Diş Hekimliği Fakültesi, Protetik Diş Tedavisi Anabilim Dalı 
dikkat edilir. Hastalarda herhangi bir sistemik rahatsızlık varsa bunun etyolojisinin belirlenmesi, ağız içi değerlendirilmesinde önemlidir. Doğru sistemik anamnez doğru ilaç bildirimi istenmeyen farmakolojik etkileşiminin oluşmasını engeller. ${ }^{10,11}$ Hastalar, tedavilerde yapılacak işlemler hakkında bilgilendirilmiş olduğu yazılı bir evrağı okumalı, anladıklarını belirtmek için de imzalamalıdırlar. ${ }^{2}$ Sabit protetik restorasyonların uzun dönem başarısı hekim tarafından verilecek doğru endikasyona bağlıdır. ${ }^{12}$ İyi bir diagnoz, uygun tedavi planı ve hastanın gerçekçi beklentileri üzerine konuşmak restorasyonun başarısı için önemlidir. ${ }^{7,13}$ Protetik tedaviye başlamadan önce hastaların çekilmesi gereken dişlerinin çekilmiş, lezyonlu dişlerinin tedavi edilmiş ve periodontal tedavilerinin bitmiş olması gerekmektedir. Dişlerde restorasyon için hazırlık yaparken kullanılacak frezler üretici firmanın önerdiği sayıda kullanılmalıdır. ${ }^{14,15}$ Retraksiyon aynı tip ip ve/veya kimyasal ajanla yapılmalıdır ${ }^{16}$. Ölçü alırken de en net sonuç verebilecek malzeme seçilmelidir. ${ }^{17-19}$ Yapılan geçiciler bitim restorasyonuna rehber olmaIıdır. ${ }^{20}$ Laboratuara gönderilen ölçülerin hepsi belirlenen alçı ile hazırlanmalıdır. ${ }^{21,22}$ Mum modelaj ve üst yapı restorasyonu da aynı teknik ekip tarafından devam ettirilmelidir. Restorasyonların ağız içi uzun dönem başarılarında, doğru siman seçiminin ve doğru simantasyon tekniğinin önemi fazladır. . ${ }^{23-26}$

Restorasyonların daha uzun süre ağızda kalabilmesi için hastalar 6 aylık aralıklarla kontrole çağrımalıdır. Hasta ve restorasyonla ilgili bilgiler hekimin arşivininde saklanmalıdır. Restorasyonun devamlıı̆̆ hastanın göstereceği dikkat ile orantılıdır². Hasta ağzındaki restorasyonlar; klinik olarak kabul edilmezse değiştirilmelidir. ${ }^{7}$

1960'lar da dişhekimliği malzemeleri için klinik takip ve uygulama yöntemleri araştırılmaya başlanmış ve standardize edebilmek için Ryge veya United States Public Health Services System (USPHS) kriteri ile standart hale sokulmaya çalışılmıştır. ${ }^{27} \mathrm{Bu}$ amaçla USPHS klinik değerlendirme kriterleri kullanılmaya başlanmıştır (Tablo1). Restorasyonların klinik değerlendirmelerinde restorasyonların komşu diş ve/veya restorasyonlarla olan renk uyumlarına, restorasyonların bitim sınırlarında renklenmenin olup olmadığına, restorasyonların anatomik formlarının devamlıı̆ıına, bitim sınırındaki adaptasyonlarına ve sekonder çürük olup olmadığına göre değerlendirmeleri yapılır. Tüm bu veriler sonucunda klinik olarak kabul edilebilir olup

olmadığına karar verilir. Restorasyonların klinik olarak uygun olma durumu iki ayrı grupta değerlendirilir; ideal restorasyonlar Alfa olarak adlandırılırken, kabul edilebilir restorasyonlar Bravo olarak belirtilir. Klinik olarak uygun olmayanlar ise, restorasyonun çevre dokulara zarar verme durumunda kısa süre de değiştirilmesi gereken restorasyonlar Charlie, hemen değiştirilmesi gereken restorasyonlar Delta olarak belirtilir. ${ }^{28,29}$

Tablo 1. USPHS klinik değerlendirme kriterleri

\begin{tabular}{|c|c|c|}
\hline Kategori & Açıklama & Değerlendirme \\
\hline \multirow[t]{3}{*}{$\begin{array}{l}\text { Renk } \\
\text { Uyumu }\end{array}$} & $\begin{array}{l}\text { Restorasyon diş rengine, } \\
\text { tonuna veya seffaflığına } \\
\text { uygundur }\end{array}$ & Alfa \\
\hline & $\begin{array}{l}\text { Dişle renk, ton ve seffaflık } \\
\text { olarak tam uygun değildir. } \\
\text { Ama yan dişle uyum } \\
\text { içindedir }\end{array}$ & Bravo \\
\hline & $\begin{array}{l}\text { Dişle renk, ton ve seffaflık } \\
\text { olarak tam uygun değildir. } \\
\text { Yan dişlede uyum içinde } \\
\text { değildir }\end{array}$ & Charlie \\
\hline \multirow[t]{3}{*}{$\begin{array}{l}\text { Marjinal } \\
\text { Renklenme }\end{array}$} & $\begin{array}{lcr}\text { Restorasyon } & \text { ile } & \text { diş } \\
\text { arasındaki } & \text { marjinlerin } \\
\text { herhangibir } & \text { yerinde } & \text { renk } \\
\text { farkı yoktur } & & \\
\end{array}$ & Alfa \\
\hline & $\begin{array}{l}\text { Renklenme vardır ama } \\
\text { pulpaya yönüne } \\
\text { ilerleme yoktur }\end{array}$ & Bravo \\
\hline & $\begin{array}{l}\text { Renklenme vardır ama } \\
\text { pulpaya yönüne doğru } \\
\text { ilerleme vardır }\end{array}$ & Charlie \\
\hline \multirow{3}{*}{$\begin{array}{l}\text { Anatomik } \\
\text { Form }\end{array}$} & $\begin{array}{l}\text { Restorasyon dişin devamını } \\
\text { anatomi yapısı içindedir }\end{array}$ & Alfa \\
\hline & $\begin{array}{l}\text { Restorasyon anatomik } \\
\text { formun aynısı değil ama } \\
\text { kabul edilebilir miktardadır }\end{array}$ & Bravo \\
\hline & $\begin{array}{l}\text { Dentin açıkta olacak şekilde } \\
\text { anatomik form yetersiz } \\
\text { olduğu durumdur }\end{array}$ & Charlie \\
\hline \multirow[t]{4}{*}{$\begin{array}{l}\text { Marjinal } \\
\text { Adaptasyon }\end{array}$} & $\begin{array}{l}\text { Gözle görünür herhangibir } \\
\text { açıklık olmaması ve sondun } \\
\text { takıldığı bir yüzey yoktur }\end{array}$ & Alfa \\
\hline & $\begin{array}{l}\text { Gözle az bir açıklık olması ve } \\
\text { bu açıklığa sondun } \\
\text { takılmasıdır }\end{array}$ & Bravo \\
\hline & $\begin{array}{l}\text { Sond dentine } \begin{array}{r}\text { veya } \\
\text { restorasyonun } \\
\text { doğru ilerler }\end{array} \\
\end{array}$ & Charlie \\
\hline & $\begin{array}{ll}\text { Restorasyon } & \text { tamamiyle } \\
\text { hareketli olması } & \\
\end{array}$ & Delta \\
\hline \multirow[t]{2}{*}{$\begin{array}{l}\text { Sekonder } \\
\text { Çürük }\end{array}$} & $\begin{array}{l}\text { Margin kenarında } \\
\text { herhangibir yumuşaklık ve } \\
\text { sekonder çürük yoktur }\end{array}$ & Alfa \\
\hline & Çürük olduğu durum & Delta \\
\hline
\end{tabular}


USPHS sistemi, restorasyonların kalitesi değerlendirilirken başarının derecesinden çok, restorasyonun kabul edilebilirliğini belirleyecek şekilde hazırlanmıştır. Anatomik form, marjinal adaptasyon ve marjinal renklenme gibi değerlendirme kriterlerinde meydana gelen küçük değişiklikleri belirlemede yeterli hassasiyete sahip değildir. Bu amaçla Modifiye USPHS yada Ryge kriterleri olarak adlandırılan klinik değerlendirme kriterleri kullanılmaya başlanmıştır (Tablo2). ${ }^{30-32}$

Tablo 2. Modifiye USPHS-Ryge klinik değerlendirme kriterleri

\begin{tabular}{|c|c|c|c|}
\hline Kategori & + & - & Direkt Klinik Değerlendirme Kriterleri \\
\hline \multirow{4}{*}{$\begin{array}{l}\text { Anatomik } \\
\text { form }\end{array}$} & 0 & & Restorasyon diş anatomisine uyumlu \\
\hline & 1 & & $\begin{array}{l}\text { Konturları hafif eksik yada hafif taşkın } \\
\text { konturlu; marjinleri hafif eksik, kontak } \\
\text { hafif açık, okluzal yükseklik lokal olarak } \\
\text { azalmış }\end{array}$ \\
\hline & & 2 & $\begin{array}{l}\text { Eksik konturlu, dentin yada kaide açıkta, } \\
\text { kontak hatalı, kendi kendine düzelemez, } \\
\text { okluzal yükseklik azalmış, okluzal } \\
\text { etkilenmiş }\end{array}$ \\
\hline & & 3 & $\begin{array}{l}\text { Restorasyon eksik yada travmatik } \\
\text { okluzyon, restorasyon dişte yada komşu } \\
\text { dokularda ağrıya sebep oluyor }\end{array}$ \\
\hline \multirow[t]{5}{*}{$\begin{array}{l}\text { Marjinal } \\
\text { adaptasyon }\end{array}$} & 0 & & $\begin{array}{l}\text { Restorasyon mevcut anatomik forma } \\
\text { uygun, sond takılmıyor }\end{array}$ \\
\hline & 1 & & $\begin{array}{l}\text { Sond takılıyor, ancak sondun gidebileceği } \\
\text { kadar açıklık yok }\end{array}$ \\
\hline & 2 & & Marjinde, mine açıkta \\
\hline & & 3 & $\begin{array}{l}\text { Marjinde bariz açıklık var; dentin ve } \\
\text { kaide açıkta }\end{array}$ \\
\hline & & 4 & Restorasyon mobil, kırık yada eksik \\
\hline \multirow{5}{*}{$\begin{array}{l}\text { Renk } \\
\text { uyumu }\end{array}$} & 0 & & Çok iyi, hemen hemen ayırt edilemiyor \\
\hline & 1 & & İyi \\
\hline & 2 & & $\begin{array}{l}\text { Hafif değişiklik var, gölge yada } \\
\text { translusensi var }\end{array}$ \\
\hline & & 3 & Bariz bir değişiklik var \\
\hline & & 4 & Renk çok fazla değişmiş \\
\hline \multirow{4}{*}{$\begin{array}{l}\text { Marjinal } \\
\text { renkleşme }\end{array}$} & 0 & & Renkleşme yok \\
\hline & 1 & & Hafif boyanmış, cila ile uzaklaştırılabilir \\
\hline & 2 & & Bariz boyanmış, cila ile uzaklaştırılamaz \\
\hline & & 3 & Çok boyanmış \\
\hline \multirow[t]{2}{*}{$\begin{array}{l}\text { Sekonder } \\
\text { çürük }\end{array}$} & 0 & & $\begin{array}{l}\text { Restorasyon marjininde çürük belirtisi } \\
\text { yok }\end{array}$ \\
\hline & & 1 & $\begin{array}{l}\text { Restorasyon marjini boyunca çürük } \\
\text { mevcut }\end{array}$ \\
\hline \multirow{4}{*}{$\begin{array}{l}\text { Yüzey } \\
\text { pürüzlülüğü }\end{array}$} & 0 & & Düzgün yüzey \\
\hline & 1 & & Hafif düzensiz ve pürüzlü yüzey \\
\hline & 2 & & Pürüzlü yüzey, tekrar düzeltilemez \\
\hline & & 3 & $\begin{array}{l}\text { Yüzeyde derin çentikler ve düzensiz } \\
\text { oluklar mevcut }\end{array}$ \\
\hline
\end{tabular}

(+): 'klinik olarak kabul edilebilir', (-):'klinik olarak kabul edilemez'

Modifiye USPHS ile değerlendirmelere kronların kontakları, ${ }^{33}$ dişlerde simantasyon sonrası oluşabilecek post operatif hassasiyette ${ }^{34}$ katılmıştır. Klinik değerlendirmelerde sıklıkla kullanılan bir diğer sistemde 1973 yılında California Dental Association'ın (CDA) (Tablo 3) geliştirdiği sistemdir. Bu sistem iki bölüme ayrılmış olup 'klinik olarak kabul edilebilir' restorasyonlar yada 'klinik olarak kabul edilemez' restorasyonlar olarak belitilirler. Her iki temel grupta ikişer alt grup içerir. ${ }^{35-37}$

Böylece hekimin, ağızdaki mevcut restorasyonları değerlendirmesi sağlanmış olur. Klinik takiplerde birden fazla hekimin değerlendirmesine dayalı olan karşılaştırma yöntemlerinde hekimlerin ortak bir kararda birleşmesi gerekmektedir. ${ }^{5,38}$

Tablo 3. CDA klinik değerlendirme kriterleri

\begin{tabular}{|c|c|}
\hline Değerlendirme & KLİNİK OLARAK KABUL EDILEBILIR \\
\hline Romeo (R) & $\begin{array}{l}\text { Klinik kalite ve profesyonel performans } \\
\text { mükemmel }\end{array}$ \\
\hline \multirow[t]{2}{*}{ Sierra $(S)$} & Klinik kalite kabul edilebilir \\
\hline & KLİNİK OLARAK KABUL EDILEMEZ \\
\hline Tango $(\mathrm{T})$ & $\begin{array}{l}\text { Restorasyonun tekrarlanması, } \\
\text { değiştirilmesi yada düzeltilmesi } \\
\text { gerekmekte, ilerki dönemde hastanın } \\
\text { dental sağlı̆ı̆ı ve çiğneme sistemine } \\
\text { zararlı etkileri olabilir. }\end{array}$ \\
\hline Victor (V) & $\begin{array}{l}\text { Restorasyonun derhal değiştirilmesi } \\
\text { gerek, çünkü hasar vermeye başlamış } \\
\text { yada ciddi yetersizlikler mevcut }\end{array}$ \\
\hline
\end{tabular}

Restorasyonların devamlılı̆ı yumuşak doku sağlığı ile yakından ilişkilidir. Restorasyonların periodontal dokulara etkisini inceleyen klinik araştırmalar, zayıf marjinal adaptasyonun, dişeti altına uzanan derin marjin yerleşiminin, pürüzlü restorasyon yüzeylerinin ve taşkın konturlü restorasyonların lokalize periodontal enflamasyona yol açtığı bildirilmiştir. ${ }^{39-42}$ Periodontal değerlendirme ilk bir ay sonra sondla kontrol edilmelidir. Restorasyonun etrafındaki enflamasyonu belirlemede sıklıkla Löe ve Silness Plak İndeksi ve Gingival İndeks Skalası kullanılır. Gingival indeks skorları orjinal verilerdir. Bu verilerin klinik olarak değerlendirilmeleri için kontrol diş olarak aynı dişin simetrisindeki diş seçilir. O diş yoksa karşı arktaki aynı diş seçilebilir. Gingival indeks değerleri hastaların kontrol seanslarında artma gösteriyorsa bu dişetinde enflamasyon olarak yorumlanabilir. ${ }^{30,43}$

Klinik çalışmalarda uygulanacak restorasyonun iç yapısı ve yapıştıktan sonraki marjinal aralıkları taramalı elektron mikroskobu veya SEM (Scanning Electron Microscope) ile analiz edilerek klinik olarak kabul edilen aralık içinde olup olmadığına bakılabilir. ${ }^{44-46}$ Ayrıca restorasyonların simantasyon sonrası bitim sınırlarının kontrolleri için restorasyonlardan alınan

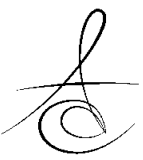


ölçülerden elde edilen epoksi rezin modeller üzerinde SEM ile incelemeler yapılabilir. ${ }^{47}$

Işık mikroskobuna alternatif olarak kullanılan elektron mikroskoplarla yapılan ölçümler klinik çalışmalarda kullanılan malzemelerin değerlendirilmesinde daha ayrıntılı bilgi vermektedir. ${ }^{5,48,49}$ Mikro sızıntı gibi daha ayırıı özelliklerin belirlenmesinde transmission elektron mikroskopu ile daha detaylı değerlendirme yapılabilmektedir. ${ }^{49-51}$

Restorasyonların klinik takiplerde kemik desteği de kontrol edilmeli bunun için gerekli görüldüğünde ${ }^{52}$ periapikal röntgen yöntemiyle kök ucu kontrolu yapılabilir.

Restorasyonlarda ve/veya karşı arktaki dişlerde karşımıza çıkan aşınmaların değerlendirmesi için restorasyon yapılan dişin karşı arkındaki dişlerden replika alınarak SEM ile incelemeleri yapılabilir. ${ }^{53-55}$

Yapılan çalışmalarda verilerin toplanması ve analiz edilmesi önemlidir. İstatistik verilerin sağ|ıkı değerlendirilebilmeleri için 19 . yüzyllın başında Amerikalı araştırmacılar yeterli bir çalışma için, çalışmadaki hastaların aynı sosyal grup içinde olmasının, doğru bir sonuç elde etmek için yeterli sayıda hasta olmasının gerekli olduğunu belirtmişlerdir. 5,56 Gore ve Altman, ilk defa istatistiğin önemini açıklamışlardır. ' $p$ ' değeri, üretilen materyal veya sanayide kullanılan materyaller için 'evet' veya 'hayır' cevabının verilmesi için kullanılmaya başlanmıştır. Birçok çalışmada $\mathrm{p}$ değeri çok küçük değişiklik göstermektedir. ${ }^{5,57}$

\section{SONUÇ}

Yapılan in vivo çalışmalar sayesinde hasta ağzında en sağlıklı şekilde kullanılacak malzemeler belirlenebilmektedir. Çalışmalarda mümkün olduğu kadar standart oluşturarak klinik başarı ve başarısızlık nedenleri daha net ortaya konulabilir.

\section{KAYNAKLAR}

1. Hess DR, Retrospective Studies and Chart Reviews. Respir Care 2004;49:1171-4.

2. Kenneth MA, Socransky SS. Survival of Dicor glassceramic dental restoration over 14 years. Part II: Effect of thickness of Dicor material and design of tooth preparation. J Prosthet Dent 1999;81:662-7.
3. Holm C, Tidehag P, Tillberg A, Molin M. Longevity and quality of FPDs: $A$ retrospective study of restorations 30,20 , and 10 years after insertion. Int J Prosthodont 2003;16:283-9.

4. DeRoy PG Helsinki and the Declaration of the Helsinki. World Med J 2004;50:9-11.

5. Randall RC, Wilson NHF. Clinical testing of restorative materials some historical landmarks. J Dent 1999;27:543-50.

6. Marks RG. The Future of Web-based Clinical Research in Dentistry. J Dent Res 2004;83: 25-8.

7. Mjör IA, Moorhead JE. Reason for replacement of restorations in permanent teeth in general dental practice. Int Dent Journal 2000;50:361-6.

8. Heintze SD, Rousson V. Survival of zirconia- and metal-supported fixed dental prostheses: A systematic review. Int J Prosthodont 2010;23:493502.

9. Şirin Ş, Özcan İ. Oral Diagnoza Giriş. Oral Diagnoz İstanbul Üniversitesi 1997 p:1-16.

10. Dresser GK., Bailey DG., Carruthers SG. Grapefruit juice-felodipine interaction in the elderly. Clin Pharmacol Ther 2000; 68: 28-34.

11. Gómez-Moreno G, Guardia J, Cutando A, CalvoGuirado JL. Pharmacological interactions of vasoconstrictors. Med Oral Patol Oral Cir Bucal. 2009;14:20-7.

12. Von Steyern PV, Carlson P, Nilner K. All-ceramic fixed partial dentures designed according to the DC-Zirkon_technique. A 2-year clinical study, J of Oral Rehabilitation 2005; 32: 180-7.

13. Goodacre CJ, Bernal G, Rungcharassaeng K, Kan JYK Clinical complications in fixed prosthodontics. J Prosthet Dent 2003;90:31-41.

14. Mou S, Chai T, Wang J, Shiau Y. Influence of different converges angles and tooth preparation heights on the internal adaptation of Cerec crowns. J Prosthet Dent 2002;87:248-55.

15. Sundh B, Köhler B. An invivo study of the impact of different emergence profiles of procera titanium crowns on quantity and quality of plaque. Int J Prosthodont 2002:15:457-60.

16. Ferrari M, Cagidiaco M, Ercoli C. Tissue management with a new gingival retraction material: A preliminary clinical report. J Prosthet Dent 1996;75:42-7. 
17. Guidance for Industry and FDA Staff Dental Impression Materials -Premarket Notification Document issued on: August 17, 1998.

18. Gracis S, Fradeani M,Celletti R, Bracchetti G. Biological integration of aesthetic restorations: Factors influencing appearence and long-term success. Periodontology 2000.2001:27:29-44.

19. Csempesz F, Vảg J, Fazekas Â. In vitro kinetic study of absorbency of retraction cords J Prosthet Dent 2003;89:45-9.

20. Patras M, Naka O, Doukoudakis S, Pissiotis A. Management of provisional restorations' deficiencies: A literature review. J Esthet Restor Dent 2012;24:26-38.

21. Shillinburg T. Fundamentals of fixed prosthodontics. Quintessence Publishing Co. Inc. 1978: 255-69.

22. Boening $K W$, Wolf $B H$, Schmidt $A E$, Kastner $K$, Walter $\mathrm{MH}$. Clinical fit of Procera AllCeram crowns . J Prosthet Dent 2000;84:419-24.

23. Pilo $R$, Cardash HS. In vivo retrospective study of cement thickness under crowns. J Prosthet Dent 1998;79:621-5.

24. Mitchell CA, Abbariki M, Orr JF. The influnce of luting cement on the probabilities of survival and modes of failure of cast full-coverage crowns. Dent Mater 2000;16:198-206.

25. Kern M, Wagner S. Bonding to zirconia ceramic: adhesion methods and their durability Dent Mater 1998;14:64-71.

26. Morgano SM., Brackett SE. Foundation restorations in fixed prosthodontics: current knowledge and future needs J Prosthet Dent 1999;82:643-57.

27. Anusavice KJ. Standardizing failure, success, and survival decisions in clinical studies of ceramic and metal-ceramic fixed dental prostheses. Dent Mater 2012;28:102-11

28. Sailer I, Bonani T, Brodbeck U, Hämmerle $\mathrm{CH}$. Retrospective clinical study of single-retainer cantilever anterior and posterior glass-ceramic resin-bonded fixed dental prostheses at a mean follow-up of 6 years. Int J Prosthodont 2013;26:443-50.
29. Monaco C, Ferrari M, Caldari M, Baldissara P, Scotti $R$. Comparison of 2 bonding systems and survival of fiber-reinforced composite inlay fixed partial dentures. Int J Prosthodont 2006;19:577-85.

30. Kükrer D. Targis inleylerin klinik performansının ve marjinal adaptasyonunun incelenmesi. Marmara Üniversitesi Protetik Diş Tedavisi Anabilim Dalı Doktora Tezi.

31. Gemalmaz D, Özcan M, Alkumru HN. A Clinical Evaluation of Ceramic Inlays Bonded with Different Luting Agent. J Adhesive Dent 2001;3:273-83.

32. Friedl KH, Schmalz G, Hiller A, Saller A. In vivo evaluation of a felspathic ceramic system: 2 year results. J Dent 1996;24:2531.

33. Bindl A, Mörmann WH. An up to 5-Year Clinical Evaluation of Posterior In-Ceram CAD/CAM Core Crowns Int J Prosthodont 2002;15:451-6.

34. Jordan RE. Adhesives in dentistry-clinical consideration. Operative Dentistry 1992;Suppl 5:95-102.

35. 35-Poggio CE, Dosoli $R$, Ercoli $C$. A retrospective analysis of 102 zirconia single crowns with knifeedge margins. J Prosthet Dent 2012;107:316-21.

36. Salido MP, Martinez-Rus F, del Rio F, Pradies G, Ozcan M, Suarez MJ. Prospective clinical study of zirconia-based posterior four-unit fixed dental prostheses: four-year follow-up. Int J Prosthodont 2012;25:403-9.

37. Beier US, Kapferer I, Burtscher D, Dumfahrt H. Clinical performance of porcelain laminate veneers for up to 20 years. Int J Prosthodont 2012;25:7985.

38. Sjögren G, Lantto R, Granberg A, Sundström $B$, Tillberg A. Clinical Examination of LeuciteReinforced Glass-Ceramic Crowns (Empress) in General Practice: A Retrospective Study. Int J Prosthodont 1999;12:122-8.

39. Schätzle $M$, Land NP, Anerud A, Boysen $H$, Bürgin $W$, Löe $H$. The influence of margins of restorations of the periodontal tissues over 26 years. J Clin Periodontol 2001;28:57-64.

40. Kancyper SG, Koka S. The influence of intracrevicular crown margins on gingival health: Preliminary findings. J Prosthet Dent 2001;85:4615.

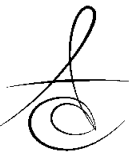


41. Reitemeier B, Hänsel K, Walter MH, Kastner C, Toutenburg $\mathrm{H}$. Effect of posterior crown margin placement on gingival health J Prosthet Dent 2002;87:167-72.

42. Bollen CML, Lambrechts $P$, Quirynen $M$. Comparison of surface roughness of hard materials to the threshold surface roughness for bacterial plaque retention: A review of the literature. Dent Mater 1997;13:258-69.

43. Carranza FA, Newman MG. Clinical Periodontology WB Saunders Company $1996,8^{\text {th }}$ Edition.

44. White SN, Yu Z, Tom JF, Sangsurasak S. In vivo marginal adaptation of cast crowns luted with different cements. J Prosthet Dent 1995;74:25-32.

45. Kokubo Y, Nagayama Y, Tsumita M, Ohkubo C, Fukushima S, Vult von Steyern P. Clinical marginal and internal gaps of In-Ceram crowns fabricated using the GN-I system. J Oral Rehabil 2005;32:753-8.

46. Quante K, Ludwig K, Kern M. Marginal and internal fit of metal-ceramic crowns fabricated with a new laser melting technology. Dent Mater 2008;24:1311-5.

47. Van Dijken JWV, Hörstedt P. The effect or pretreatment with an oxalic acid solution on marginal adaptation to enamel in vivo. J Prosthet Dent 1998;80:75-80.

48. Hannig M. Transmission electron microscopic study of in vivo pellicle formation on dental restorative materials. Eur J Oral Sci 1997; 105:422-33.

49. Hannig M. Transmission electron microscopy of early plaque formation on dental materials in vivo. Eur J Oral Sci 1999;107:55-64

50. Hannig M. Transmission electron microscopic study of in vivo pellicle formation on dental restorative materials. Eur J Oral Sci 1997; 105:422-33

51. Ayyıldız S, Uyar A, Yüzügüllü B. Diş Hekimliğinde Mikrosızıntı Ve İnceleme Yöntemleri. Atatürk Üniv Dis Hek Fak Derg 2009; 19: 219-26

52. Von-Steyern $P$, Jönsson $O$, Nilner K. Five-Year Evaluation of Posterior All-Ceramic Three-Unit (InCeram) FPDs. Int J Prosthodont 2001;14:379-84

53. Ekfelt A, Öılo G. Wear of prosthodontic materialsan in vivo study. J Oral Rehab 1990;17:117-29,
54. Dahl BL, Öılo G. In vivo wear ranking of some restorative materials. Quintessences Int 1994;25:561-5

55. Magne P, Oh WS, Pintado MR., DeLong R.Wear of enamel and veneering ceramics after laboratory and chairside finishing procedures $\mathrm{J}$ Prosthet Dent 1999;82:669-79

56. Altman DG., Bland JM., Improving Doctors' Understanding of Statistics. J R Statist Soc 1991; 154: 223-67

57. Walton TR, Layton DM. Cost satisfaction analysis: A novel patient-based approach for economic analysis of the utility of fixed prosthodontics. J Oral Rehabil 2012;39:692-703

\section{Yazışma Adresi}

Yrd. Doç. Dr. Ayşe KOÇAK-BÜYÜKDERE

Kocaeli Üniversitesi

Diş Hekimliği Fakültesi

Yuvacık Yerkleşkesi

41190 Yuvacık - Başiskele

Kocaeli Türkiye

Tlf: + 905323165759

Faks: + 902623442109

e-mail: kocakayse@yahoo.com 